\title{
REPEATED BLOOD SUGAR CURVES IN NON-DIABETIC SUBJECTS ${ }^{1}$
}

\author{
By WILLIAM G. LENNOX ${ }^{2}$
}

With the Assistance of Margaret Bellinger

\begin{abstract}
(From the Laboratory of the Department of Neuropathology, Harvard Medical School, the Medical Service of the Massachusetts General Hospital and the Thorndike Memorial Laboratory of the Boston City Hospital)
\end{abstract}

(Received for publication February 24, 1927)

Various authors who have made duplicate blood sugar curves from the same individuals have considered that any lowering of the second curve was the result of the treatment or of the experimental procedure introduced. The following may be mentioned as examples: lowered curves in 6 patients better of arthritis (1), and in 6 of 10 patients following medication by means of vasodilator drugs, Pemberton et al. (2); in 7 of 12 subjects, second curves with patients sitting which were lower than initial curves with limbs elevated, Cajorie et al. (3); in four patients lowered curves accompanying reduction in weight, Labbe (4); lowered curves following arc light irradiation, Berg (5), after recovery from head injuries, Davidson and Allen (6), and when tannic acid was given with the glucose, Mertz and Rominger (7). With reference to these and other reports which might be cited, the question arises whether the reduction in the height of the second curves might be due wholly or in part to a natural tendency for the second curve to be lower than the first.

Most writers have assumed that the level and the general form of the blood sugar curve of a normal individual is fairly constant from time

${ }^{1}$ This research was made possible through a grant by the Committee on Epilepsy, New York City. This paper is no. 54 in a series of studies in metabolism from the Harvard Medical School and Allied Hospitals. The expenses have teen defrayed in part by a grant from the Proctor Fund of the Harvard Medical School for the study of Chronic Diseases.

${ }^{2}$ Fellow in Medicine of the National Research Council during a portion of this research. 
to time. However, duplicate curves were found to be lower than initial curves in four of six students by Hale-White (8) and in three of five non-diabetic patients by Niemeyer (9). We have seen no reports concerning repeated curves in a large group of non-diabetic subjects.

In the course of a study of blood sugar curves on 140 persons subject to recurring loss of consciousness and convulsions (10), we found that a surprisingly large proportion (24 per cent) had a high, or prediabetic type of curve. In seeking to account for this, we repeated the test in a number of these individuals and found in more than half that the second or third curve was normal. Because we obtained a somewhat similar lowering of duplicate curves in healthy subjects, we consider that the observation is not confined to persons with epilepsy. This is a report of 50 persons in whom the blood sugar curve was repeated from one to fourteen times. In all, approximately 300 curves were determined.

\section{MATERIAL AND METHODS}

The subjects included five healthy persons and one patient with arthritis. The others were patients with symptoms of recurring convulsions. Information concerning these is contained in the previously mentioned paper (10). On initial trial, one-half of these 50 subjects showed high blood sugar curves (those which rose to above $165 \mathrm{mgm}$. and were more than $120 \mathrm{mgm}$. at the end of the second hour). This proportion of high curves is double that for the whole group of 160 persons from whom this smaller group was selected, and is, of course, much higher than would be encountered in any unselected group of non-diabetic subjects. Unless otherwise stated, the subjects were eating their usual mixed diet, which was not changed during the period of observation. We endeavored also to keep other factors which might conceivably modify the form of the curves-such as medication, activity during the test, room temperature, etc.-constant. The interval between examinations varied from a few days to a number of months. All tests were performed at least 12 hours after the ingestion of food. For the experiments in which sugar was given by mouth, we used pure dextrose in 33 per cent solution, in an amount equal to 1.5 gram per kilo of body weight, and for the tests in which sugar was injected, we used 0.33 gram per kilo of body weight of chemically pure glucose in 20 per cent watery solution. Venous blood was drawn before, and at intervals of $\mathbf{3 0}$ minutes, one and two hours after administration of the glucose. In the intravenous tests blood was collected, in addition, four minutes after the injection.

Blood was hemolized with water immediately (within 15 minutes) after withdrawal. Only sufficient oxalate to prevent clotting was used. Sugar was measured by the method of Folin-Wu, (11). Sugar tubes, as modified by Evans (12) were 
used. For the sake of brevity, we shall speak of blood sugar curves following ingestion of glucose as ingestion curves, and those following intravenous injection of glucose as intravenous curves.

\section{RESULTS}

Duplicate curves. A summary of the results of duplicate curves following ingestion or injection of glucose is given in table 1. Of the

TABLE 1

Two successive blood sugar curves following ingestion (50 cases) or intravenous injection (29 cases) of glucose

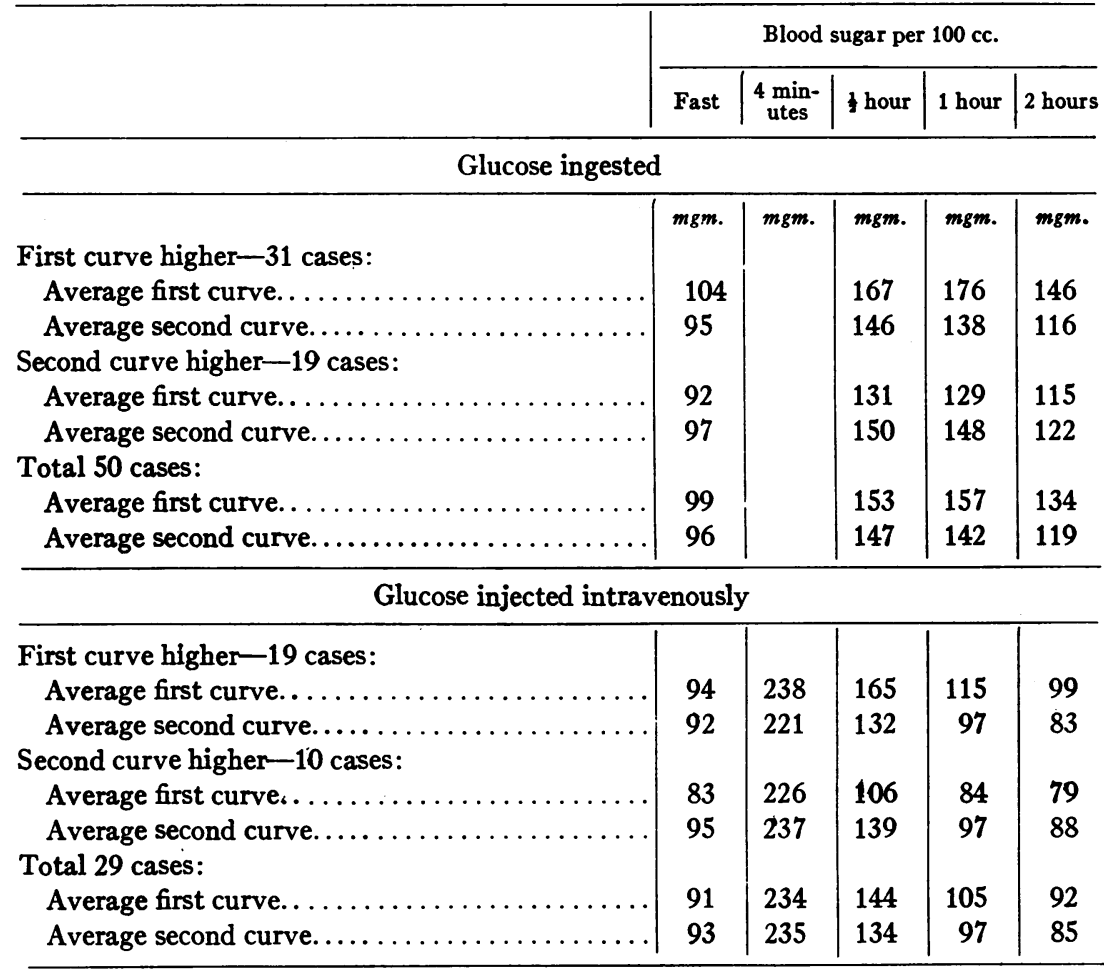

50 duplicate ingestion curves, 31 or 62 per cent were lower and 19 or 38 per cent were higher than the initial curves. Of the 25 curves which were abnormally high on first trial, 21, or 84 per cent, were lower on second trial. For the whole group of 50 persons in whom duplicate curves were drawn, the second curve was distinctly lower than the first (fig. 1). 
Table 2 gives the measurements concerning the 31 subjects in whom the second curves were lower than the first. In some the difference was negligible, in others, such as the 11 duplicate measurements shown in figure 2 , it was marked. The initial curve of many of these individuals was clearly abnormal-whereas the second curve was normal. Cases numbers 1, 2 and 3 in table 2 and figure 2 were male students with no evidence of disease on physical examination. Number 4 had chronic arthritis. In addition to

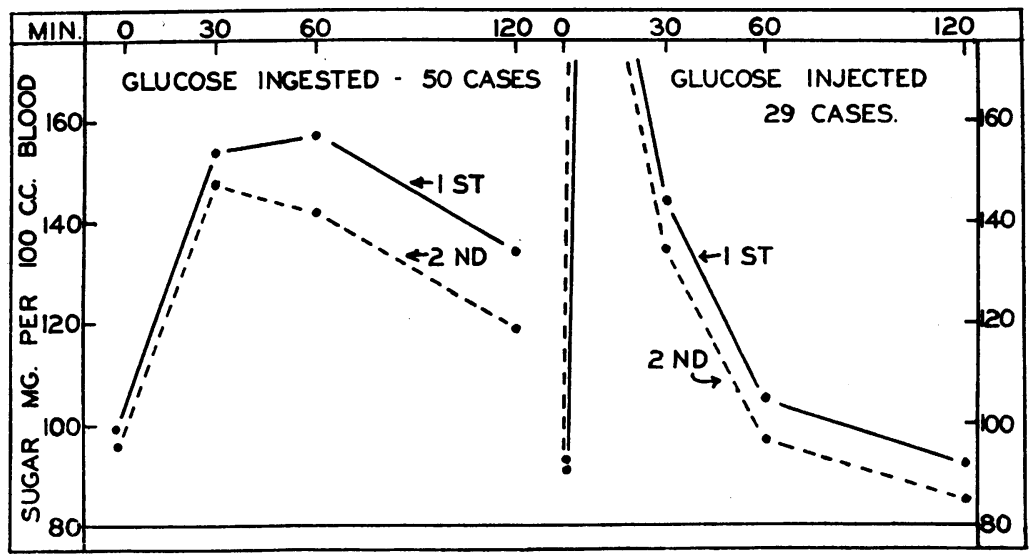

Fig. 1. Average Duplicate Blood Sugar Curves of 50 Subjects Who InGested Glucose aNd of 29 SubJects IN Whom it WAS INJected

With both methods, second curves were lower than first. In this and other charts, ordinate represents concentration of sugar in the whole blood and abscissa represents minutes. First blood was drawn with the subject fasting, and one-half, one and two hours after the administration of glucose. The four-minute values for injection curves are omitted.

epilepsy, number 7 had essential hypertension, and number 14 a strong family history of endocrine disease. The other patients presented no evident cause for the high initial curve which many of them showed. Although the successive composite curves, as shown in figures 1 and 3 , present the same shape, the configuration of many of the individual successive curves was very different.

Beeler, Bryan, Cathcart and Fitz (13) have criticized the blood sugar curve test as ordinarily performed (following the administration of 
WILLIAM G. LENNOX

TABLE 2

Thirty-one subjects whose second blood sugar curve was lower than the first

\begin{tabular}{|c|c|c|c|c|c|c|c|c|c|}
\hline \multirow{3}{*}{$\begin{array}{l}\text { Subject } \\
\text { number }\end{array}$} & \multicolumn{8}{|c|}{ Blood sugar per $100 \mathrm{cc}$. of blood } & \multirow{3}{*}{$\begin{array}{c}\text { Days } \\
\text { between } \\
\text { tests }\end{array}$} \\
\hline & \multicolumn{4}{|c|}{ First curve } & \multicolumn{4}{|c|}{ Second curve } & \\
\hline & Fast & $\frac{1}{2}$ hour & 1 hour & 2 hours & Fast & $\frac{1}{2}$ hour & 1 hour & 2 hours & \\
\hline & mgm. & mgm. & mgm. & $m g m$. & $m g m$. & $m g m$. & $m g m$. & $m g m$. & \\
\hline 1 & 123 & 133 & 148 & 165 & 109 & 130 & 137 & 100 & $7^{*}$ \\
\hline 2 & 141 & 195 & 174 & 125 & 102 & 156 & 127 & 100 & 7 \\
\hline 3 & 94 & 163 & 188 & 129 & 99 & 135 & 95 & 75 & 18 \\
\hline 4 & 94 & 168 & 182 & 186 & 93 & 149 & 175 & 128 & 1 \\
\hline 5 & 101 & 112 & 181 & 142 & 94 & 108 & 114 & 143 & 25 \\
\hline 6 & 87 & 192 & 171 & 102 & & 107 & 144 & 94 & 35 \\
\hline 7 & 121 & 211 & 286 & 164 & 79 & 131 & 208 & 135 & $275 \ddagger$ \\
\hline 8 & 88 & 152 & 144 & 132 & 90 & 127 & 135 & 137 & $63+$ \\
\hline 9 & 89 & 156 & & 222 & 90 & 146 & 190 & 150 & $295 \dagger$ \\
\hline 10 & 89 & 151 & 147 & 108 & 89 & 148 & 110 & 90 & $48 \dagger$ \\
\hline 11 & 131 & 152 & 165 & 108 & 97 & 125 & 114 & 100 & 155 \\
\hline 12 & 91 & 156 & 154 & 114 & 104 & 132 & 91 & 80 & 160 \\
\hline 13 & 95 & 145 & 146 & 133 & 85 & 100 & 81 & 91 & $175 \dagger$ \\
\hline 14 & 97 & 210 & 194 & 164 & 79 & 187 & 169 & 143 & $312 \dagger$ \\
\hline 15 & 100 & 202 & 203 & 161 & 100 & 235 & 190 & 105 & 97 \\
\hline 16 & 125 & 185 & 222 & 91 & 107 & 165 & 186 & 152 & $260^{*}$ \\
\hline 17 & 92 & 144 & 154 & 171 & 82 & 119 & 110 & 103 & $17^{*}$ \\
\hline 18 & 133 & 182 & & 211 & 92 & 129 & 114 & 90 & $130^{*}$ \\
\hline 19 & 115 & 164 & 205 & 148 & 105 & 172 & 153 & 128 & 107 \\
\hline 20 & 100 & 144 & 160 & 137 & 91 & 138 & 138 & 131 & 7 \\
\hline 21 & 94 & 179 & 143 & 133 & 87 & 118 & 95 & & $102^{*}$ \\
\hline 22 & 101 & 190 & 200 & 130 & 95 & 180 & 179 & 143 & 15 \\
\hline 23 & 100 & 174 & 198 & 186 & 99 & 142 & 149 & 147 & 4 \\
\hline 24 & 92 & 241 & 241 & 172 & 92 & 206 & 136 & 139 & 41 \\
\hline 25 & 98 & 155 & 181 & 138 & 91 & 170 & 117 & 106 & 14 \\
\hline 26 & 145 & 147 & 176 & 127 & 105 & 210 & 178 & 91 & $45^{*}$ \\
\hline 27 & 97 & 129 & 129 & 118 & 93 & 145 & 106 & 104 & $188^{*}$ \\
\hline 28 & 95 & 154 & 129 & 98 & 117 & 122 & 111 & 100 & $37 \dagger$ \\
\hline 29 & 100 & 200 & 129 & 121 & 84 & 138 & 113 & 91 & $295 \dagger$ \\
\hline 30 & 102 & 126 & 185 & 185 & 100 & 130 & 153 & 120 & $28^{*}$ \\
\hline 31 & 88 & 153 & 165 & 204 & 93 & 116 & 160 & 171 & 7 \\
\hline
\end{tabular}

* An intravenous test was done in the interval.

$\dagger$ Two intravenous tests were done in the interval.

$\ddagger$ Three intravenous tests were done in the interval.

glucose by mouth) because variable speed of absorption of glucose from the gastro-intestinal tract may seriously modify the degree of hyperglycemia. On this account, various writers have recommended 
the administration of glucose by intravenous injection. We have performed comparative blood sugar curve tests following both ingestion and injection of glucose in 100 subjects. The data obtained will be presented elsewhere (14). It is sufficient for our purpose here to point out that of 29 subjects in whom duplicate intravenous curves

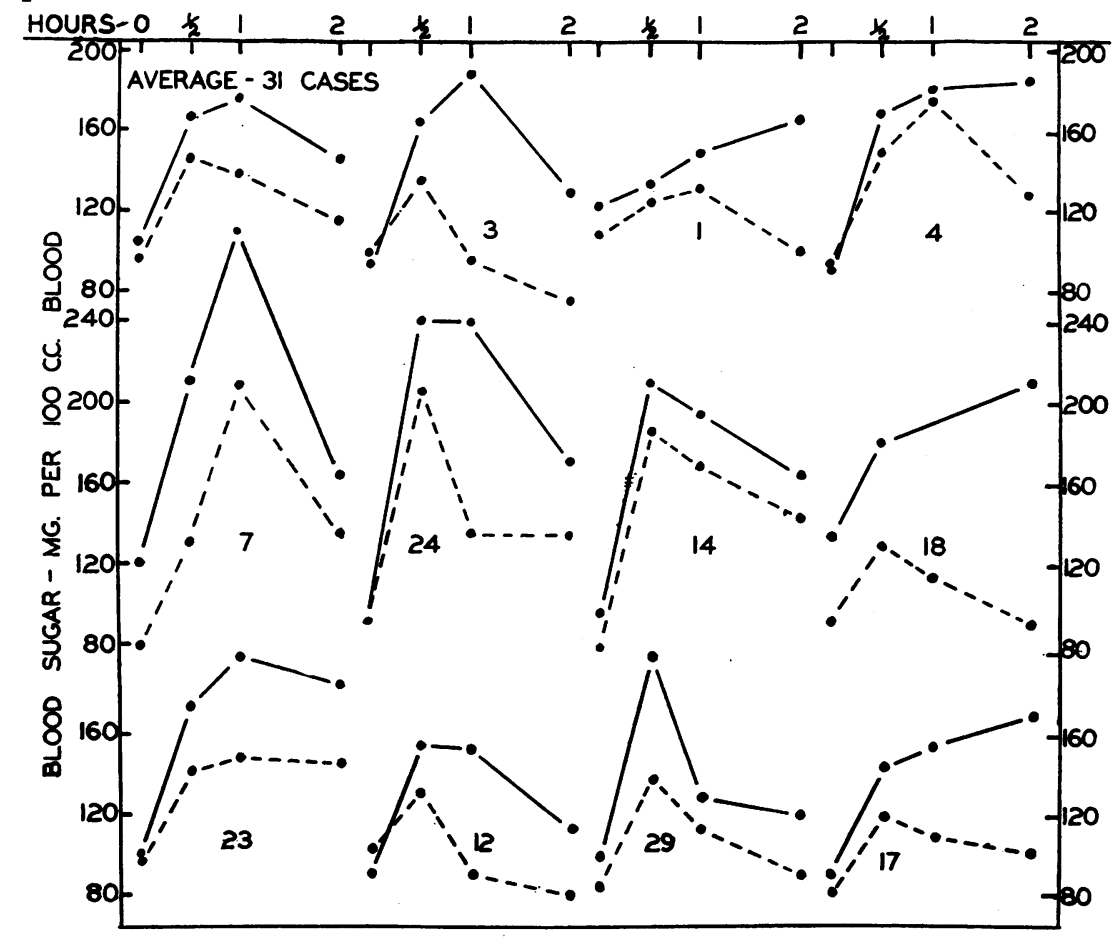

Fig. 2. First and Second Blood Sugar Curves Following Ingestion of Glucose in 11 of the Subjects Named in Table 2

The numbers on the chart refer to case numbers in table 2. The first curve given is the average of first and second curves for the 31 subjects in whom second curves were lower than first.

were drawn, the second curve was lower in 65 per cent. For all 29 subjects the average second curve was distinctly lower than the first. (Table 1 and figure 1.) The evidence is somewhat complicated by the fact that the majority of the subjects were used for the plotting of both ingestion and injection curves and, as indicated in table 2, intra- 
venous and postprandrial curves were oftentimes interspersed. However, individuals who showed most marked differences between first and second curves were not necessarily those in whom a test by a different method had been performed in the interval.

Triplicate curves. Table 3 presents the results with the 25 subjects in whom sugar curve tests following ingestion of glucose were done three times. All but one of the subjects in table 3 were patients. Examination of the table and inspection of figure 3 shows progressive lowering of each successive curve. This is seen also in the 12 subjects in whom three intravenous curves were performed. Differences

TABLE 3

Three successive blood sugar curves following ingestion (25 cases) or intravenous injection (12 cases) of glucose

\begin{tabular}{|c|c|c|c|c|c|}
\hline & \multicolumn{5}{|c|}{ Blood sugar per $100 \mathrm{cc}$} \\
\hline & Fast & 4 minutes & $\frac{1}{2}$ hour & 1 hour & 2 hours \\
\hline \multicolumn{6}{|c|}{ Glucose ingested -25 cases } \\
\hline $\begin{array}{l}\text { Average first curve } \ldots \ldots \ldots \ldots \ldots \\
\text { Average second curve } \ldots \ldots \ldots \ldots \ldots \\
\text { Average third curve.............. }\end{array}$ & $\begin{array}{r}m g m . \\
101 \\
95 \\
100\end{array}$ & mgm. & $\begin{array}{c}m g m . \\
162 \\
155 \\
150\end{array}$ & $\begin{array}{c}\text { mgm. } \\
166 \\
151 \\
140\end{array}$ & $\begin{array}{c}\text { mgm. } \\
139 \\
126 \\
119\end{array}$ \\
\hline \multicolumn{6}{|c|}{ Glucose injected intravenously-12 cases } \\
\hline $\begin{array}{l}\text { Average first curve } \ldots \ldots \ldots \ldots \ldots \\
\text { Average second curve } \ldots \ldots \ldots \ldots \ldots \\
\text { Average third curve. } \ldots \ldots \ldots \ldots \ldots\end{array}$ & $\begin{array}{r}93 \\
91 \\
101\end{array}$ & $\begin{array}{l}228 \\
253 \\
241\end{array}$ & $\begin{array}{l}158 \\
151 \\
142\end{array}$ & $\begin{array}{l}116 \\
105 \\
101\end{array}$ & $\begin{array}{r}103 \\
87 \\
83\end{array}$ \\
\hline
\end{tabular}

between successive injection curves were not as great as between successive ingestion curves. It is to be remembered that the amount of glucose injected was only slightly more than a fifth of the amount ingested.

Quadruplicate curves. Table 4 shows the average results for the 15 subjects in whom four curves were made following the ingestion of glucose. In contrast with the preceding observations, there was in this group no change in level of the successive curves, except that the third curve was lower than the other three. The explanation for the continued high curves in this group of subjects is that these more frequently repeated tests were performed on the persons whose third 
sugar curve was not normal. Most of the members of this group showed a persistently high curve no matter how often the test was repeated. The significance of this will be discussed later.

Possible causes for reduction of curves. In seeking to account for the progressive reduction in the degree of hyperglycemia which many of these subjects showed, various possible explanations need to be considered.

1. Increased speed of absorption of glucose from the gastro-intestinal tract may be a factor. Against this possibility is the fact that pro-

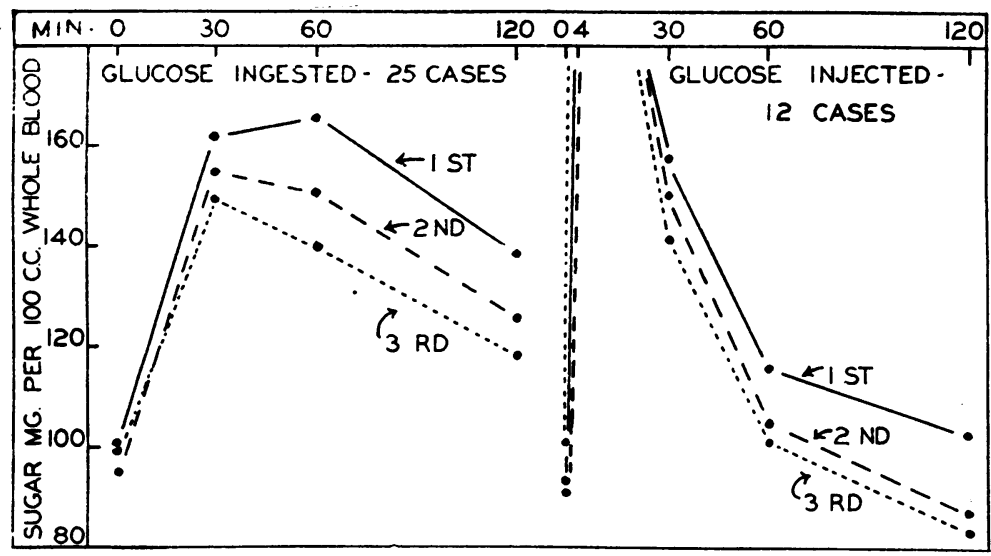

Fig. 3. Average Triplicate Blood Sugar Curves of 25 Subjects Who Ingested Glucose aNd of 12 Subjects In Whom it Was Injected

Each curve is lower than its predecessor

gressive lowering of the curve accompanied successive intravenous injections as well as successive ingestions of glucose.

2. Because most of the subjects were epileptics under treatment, the increased ability to dispose of glucose introduced into the body may be a phenomena concerned with epilepsy or may be an expression of improvement in the physical condition of patients. Such explanation would not hold for the three healthy students and the one subject with arthritis shown in figure 2 and table 2 (cases 1, 2, 3 and 4). In these subjects the interval between tests was from one to eighteen days, during which time no change was made in the diet or manner of living. Many patients, moreover, who exhibited progressive lowering 
of blood sugar curves, showed no appreciable change in their physical condition.

3. It is possible that initial curves of healthy subjects and of patients alike were higher because of excitement over the first test, with accompanying increased output of adrenalin and consequent increase in the concentration of circulating glucose. We were not able, however, to correlate initial high curves with any apparent evidence of nervousness on the part of subjects. The three students mentioned, cases 1, 2 and 3, although evidently nervous at the first trial, were still more so at the second, as they had been told that the first test showed possibility of latent diabetes.

Still more important is the evidence furnished by the subjects whose successive ingestion curves are presented in figure 4. Patient number

TABLE 4

Four successive blood sugar curves following ingestion of glucose (15 cases)

\begin{tabular}{|c|c|c|c|c|}
\hline & \multicolumn{4}{|c|}{ Blood sugar per $100 \mathrm{cc}}$. \\
\hline & Fast & $\frac{1}{2}$ hour & 1 hour & 2 hours \\
\hline & $m g m$. & mgm. & mgm. & $m g m$. \\
\hline Average first curve............. & 98 & 157 & 164 & 135 \\
\hline Average second curve........ & 95 & 155 & 161 & 135 \\
\hline Average third curve.......... & 100 & 149 & 139 & 121 \\
\hline Average fourth curve......... & 95 & 156 & 165 & 130 \\
\hline
\end{tabular}

7 was a young woman of 22 years who, in addition to infrequent, slight epileptiform seizures, had essential hypertension. For a period of six weeks before the initial sugar curve test was performed, she was the subject of experiments which required almost daily venesection. During the period of 20 months in which five ingestion and four intravenous curves were determined, her physical condition did not change materially, but her sugar curve became progressively lower (hypoglycemia in place of hyperglycemia at the end of two hours) and also showed marked alteration in configuration (the peak of the curve at the half-hour rather than at the hour). The second half of figure 4 represents the successive curves of one of us who had been the subject of experimental procedures on many previous occasions. Although the configuration of successive curves was constant, the last four curves were lower than the first two. 
4. The fourth possibility which needs to be considered is that sudden flooding of the body with pure glucose stimulated the glucose utilizing mechanism of the body to such an extent that on subsequent occasions glucose was disposed of with greater speed. Because periods of weeks or months intervened between successive tests, this conception would seem improbable. The sugar utilizing mechanism of the body would hardly "remember" a stimulus for so long a period of time. Such an explanation, however, has certain supporting evidence which will be presented.

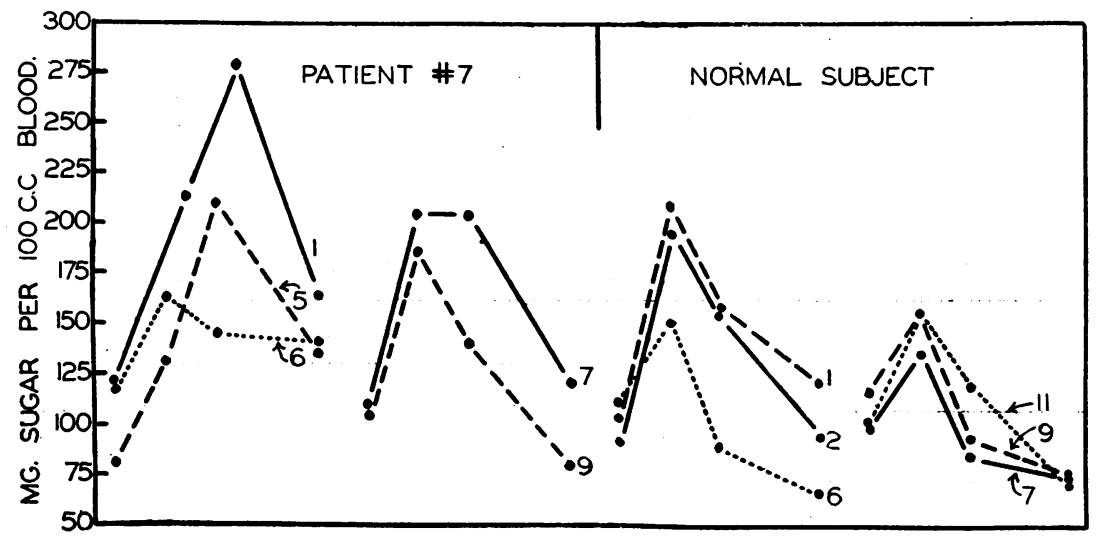

Fig. 4. Successive Blood Sugar Curves Following Ingestion of Glucose

Observations covered a period of 20 months for patient number 7 , and of 30 months for the normal subject. In both of these individuals the psychic factor as a possible cause for initial high curves could be ruled out. The numbers attached to each curve indicate the chronological order in which the tests were made. Absent numbers represent curves made by the intravenous method.

It is well known that ingestion of a second quantity of glucose an hour or two after a first may not result in any increase in the concentration of glucose in the blood. Concerning this point we have additional data which will be presented elsewhere (15). This excessive speed in the utilization of glucose is best explained by the stimulating effect of the first dose of glucose on the sugar regulating mechanism. In addition to this evidence that glucose acts as a stimulus to the pancreas, we have evidence concerning the effect of lack of such stimulation during fasting. 
Sugar curves during fasting. During fasting, as is well known, concentration of sugar in the blood is at a constant low level. Available glucose is insufficient to provide for complete combustion of fat and ketosis results. One would expect that if glucose were introduced into the body during starvation, it would be very quickly oxidized. Strangely enough, the opposite condition is true. Ingestion of glucose during fasting results in prolonged hyperglycemia. This has been shown for human subjects by Staub (16), Traugott (17), Pemberton (1) and Severinghaus (18) and for rabbits by Vigneaud and Karr (19). The last named authors found that there was delay in the disappearance from the blood stream of injected as well as of ingested glucose. So far as we are aware, the cause for this hyperglycemia has not been demonstrated. There are two factors which especially deserve consideration. First, it is possible that the acidosis of starvation may interfere with the utilization of ingested glucose. Glucose is less easily oxidized in an acid medium. Henderson (20) has recently emphasized the intimate relationship between the glucose and the acidbase equilibrium of the blood. Second, it is possible that during a fast the decreased metabolism of carbohydrates may fail to provide the sugar disposing mechanism of the body with the stimulation it needs so that glucose which is subsequently introduced is not quickly utilized. The following charts give evidence which supports the latter view.

Figure 5 presents various sugar curves made with reference to fasting and changes in the alkalinity of the blood. In each of the three patients the curve made during a fast was diabetic in type. In each there was lack of correlation between the height of curves, and the degree of acidosis, as measured by the plasma bicarbonate. For example, patient 51, whose plasma bicarbonate measured 68 volumes per cent, reacted to an initial ingestion of 100 grams of glucose with hypoglycemia. At the end of a 12 day fast, his plasma bicarbonate was nearly normal (61 volumes per cent) yet two hours after ingestion of glucose his blood sugar was $240 \mathrm{mgm}$. Patient 53 was given large doses of ammonium chloride for a period of two weeks. This produced marked acidosis (plasma bicarbonate 44 volumes per cent). Her blood sugar curve, however, was normal and much lower than before acidosis was induced. The patient was then fasted for 17 days; at the end of which time her sugar curve was diabetic in type. At this 


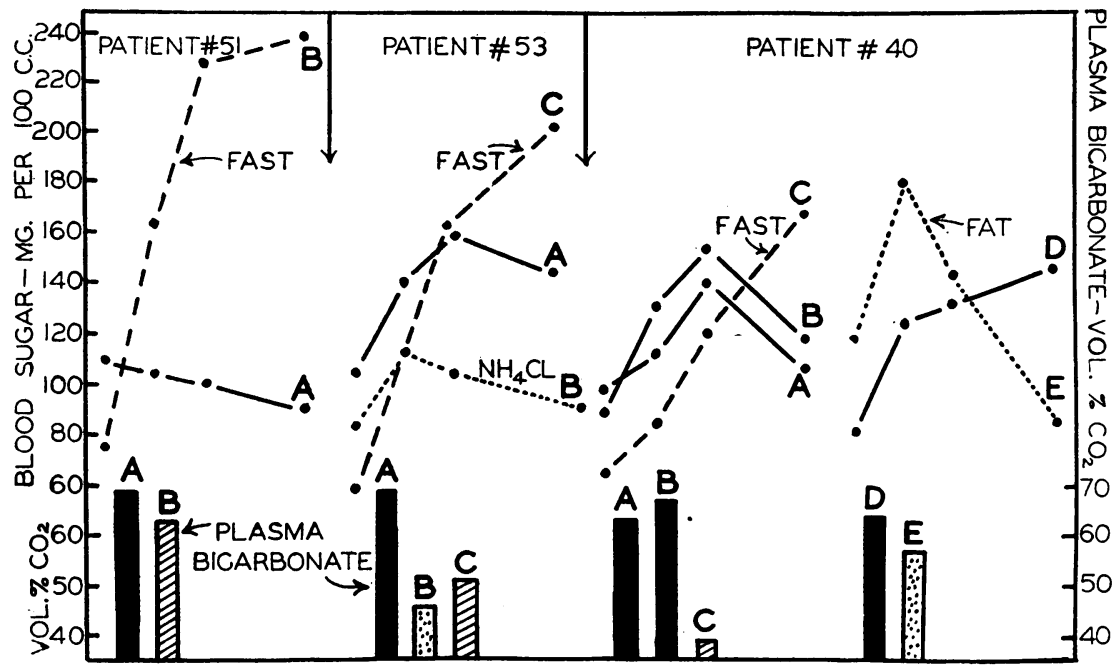

Fig. 5. Blood Sugar Curves Made During Fasting with Reference to the Degree of Acidosis Present

The columns at the bottom of the chart indicate the level of plasma bicarbonate $\left(\mathrm{CO}_{2}\right.$ combining power of the plasma) at the time the sugar curve was started. Measurements made during a fast are indicated by broken lines and hatched columns, and those made during acidosis induced by ammonium chloride or ketogenic diet by dotted lines and columns.

For patient 51, curve A was made before the fast. Curve B was made after ten days of fasting, and one day in which 60 grams of intarvin and one day in which $135 \mathrm{cc}$. of 40 per cent cream was given.

For patient 53, curves $A$ and $B$ were drawn when the patient was eating a mixed diet. Curve $B$ was made after a period of 19 days in which from 5 to 20 grams of ammonium or calcium chloride had been given daily. Curve $\mathrm{C}$ was drawn at the end of 17 days of fasting, and 24 hours after the adrenalin test shown in figure 8. It will be noted that although acidosis was greatest following administration of the acid forming salts, (44 volumes per cent $\mathrm{CO}_{2}$ ) the curve made at that time was normal.

For patient 40 , curves $\mathrm{A}$ and $\mathrm{B}$ were made at intervals of a week before the fast, and curve $\mathrm{C}$ on the sixth day of the fast. Another test attempted on the fourteenth day was unsuccessful because the glucose was vomited. Curve D was made after one day in which $100 \mathrm{cc}$. of orange juice had been drunk, and curve $\mathrm{E}$ two weeks later at the end of 14 days of ketogenic diet. Although acidosis was greater with the fat diet than after a day of fruit juice following the 14-day fast, hyperglycemia was much less prolonged. 
time acidosis was less than when ammonium chloride was used. (Plasma bicarbonate 51 volumes per cent.) Patient 40 showed a high curve (curve C) during fast, following which she was on a high calorie, fat diet for two weeks. Curve E, made at the end of this time, was not abnormally high, though ketosis was greater than at the end of the fast, when curve $\mathrm{C}$ was made.

Further evidence is presented in figure 6. This figure shows successive sugar curves made at intervals during a fast of patient 38. These curves were made following ingestion of 10 grams of glucose, an amount sufficient to produce increase in blood sugar, but not sufficient to produce hyperglycemia or noticeably to effect the degree of ketosis, Inspection of figure 6 shows that the height of the sugar curves increased with the progress of the fast. The degree of acidosis, on the contrary, was greatest on the sixth day, after which it declined. We have shown elsewhere (21) that the peak of fasting acidosis, as measured by plasma bicarbonate, occurs between the third and seventh days of fasting. The curves in figure 6, as well as those given by Vigneaud and Karr, (19) demonstrate that the height of curves increases progressively with the length of the fast. We determined blood sugar curves during fasting in five subjects. The smallest reaction obtained was in the case of a patient who at the end of a 14-day fast had measurements of blood sugar while fasting and $\frac{1}{2}, 1$ and 2 hours after glucose as follows: $96,172,186$ and $165 \mathrm{mgm}$. Corresponding measurements two months later were $93,114,95$ and 97 . The fact that glycemia was not greater at the end of the fast may perhaps be explained by the fact that during the fast the patient received $\mathbf{5 4}$ grams of thyroid extract. The consequent increase of metabolism may have partially maintained stimulation of the sugar-disposing mechanism.

Adrenalin sugar curves during fasting. We were interested to determine whether hyperglycemia during fasting would result if the glucose was drawn from body stores. Figure 7 presents various curves on two patients. Patient 52 showed an increase of $22 \mathrm{mgm}$. in the concentration of blood sugar following injection of adrenalin on the eighth day of a fast. Several months later, when she was on normal diet, the test was repeated. At this time, although she gave pronounced symptoms of adrenalin reaction, there was almost no rise in blood sugar. With patient 40 the story was somewhat different. 


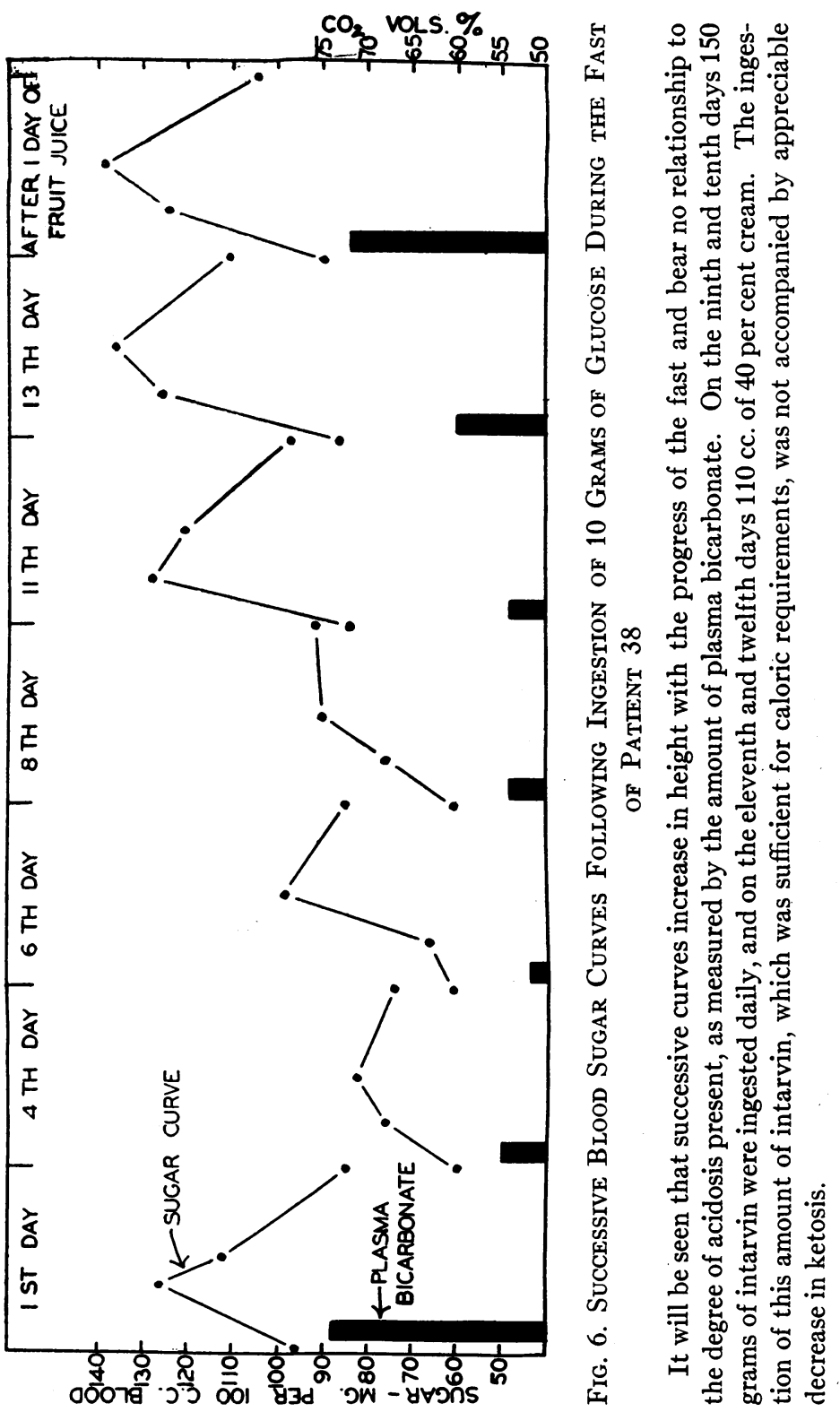


The increase in blood sugar following injection of adrenalin, when eating a mixed diet (curve A), was about equal to that which took place on the eleventh and fourteenth days of a fast. Three curves were drawn subsequent to the resumption of food: the first (curve $D$ ) after two days of orange juice, the second (curve E) after three weeks

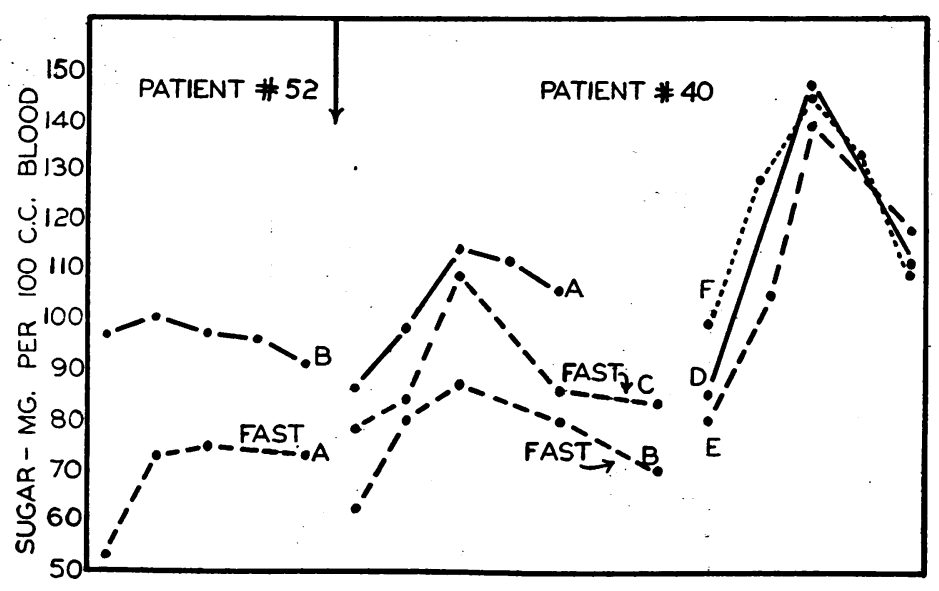

Fig. 7. Blood Sugar Measurements at Half-hour Intervals following THE INJECTION OF ADRENALIN

Patient 52 was given subcutaneous injections of $\frac{1}{2} b_{0}$ grain adrenalin. Curve A was drawn on the eighth day of the fast, (plasma bicarbonate 42.6 volumes per cent) curve B several months later, (plasma bicarbonate 60.4 volumes per cent). The patient during the last test showed marked adrenalin reaction, although blood sugar did not rise. Six curves were drawn for patient 40 , following the injection of $0.5 \mathrm{cc}$. adrenalin. Curve A was made before the beginning of the fast, curve $B$ on the eleventh day and curve $C$ on the fourteenth day of the fast. Curve $D$ was drawn following the fast and after two days in which only orange juice was ingested, curve $\mathrm{E}$ after two weeks of fat diet, and curve $\mathrm{F}$ after several months of mixed diet. Measurements for plasma bicarbonate in volumes per cent of $\mathrm{CO}_{2}$ at the beginning of various curves were as follows: A 68.5, B 44.6, C 40.2, D 63.6, E 57.1.

of ketogenic diet, and the third (curve F) after six months of normal diet. These three curves were of the same height. The fact that they were higher than the prefasting curve A may possibly be explained by the fact that preceding the determination of curve $A$, the patient for many months had been on a low carbohydrate diet, for which reason glycogen stores may have been depleted. 
Figure 8 shows contrasting curves following adrenalin injection in patient 53. The concentration of blood sugar two hours after the injection on the sixteenth day of a fast was 75 per cent above the preinjection level, against a 25 per cent increase while not fasting.

In view of the acute need of the body for glucose during starvation, it is of interest that injection of adrenalin so readily called forth additional glucose. We have no means of knowing the extent of the

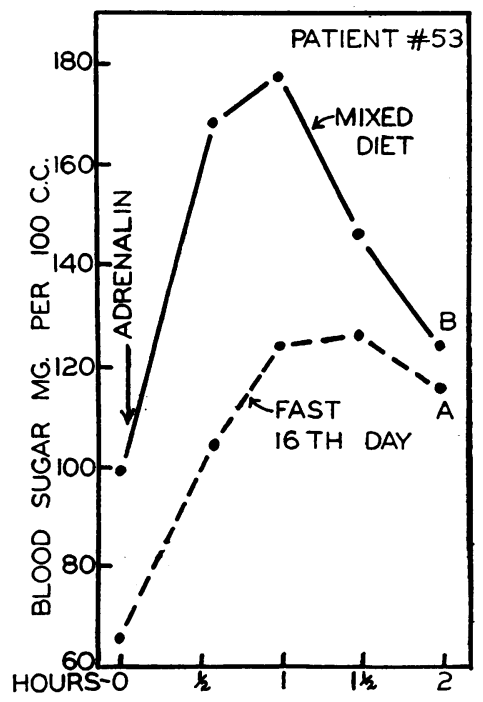

Fig. 8. Blood Sugar Curves of Patient 53 Following the Injection of ifo Grain of AdRENALIN

Curve A was made on the sixteenth day of the fast, curve B several months later. Two hours after the injection, blood sugar was 75 per cent above the fasting value in curve $A$ and 25 per cent above the fasting value in curve $B$.

glycogenolysis. Presumably, it was less during the fast than during feeding, yet the hyperglycemia following adrenalin injection was as great or greater during the fast.

These observations concerning blood sugar curves during fasting are not extensive enough to permit examination of factors other than the two mentioned. It would seem evident that of these two factors, acidosis plays only a subordinate rôle, and that the undue hyper- 
glycemia which follows ingestion of glucose during a fast may be explained by the previous diminution in stimulation of sugar disposing mechanism. Vigneaud and Karr (19) suggest this but discount the influence of hyperglycemia because in one of their experiments, in which hyperglycemia had been produced 18 hours earlier by administration of morphine, ingestion of glucose was followed by prolonged increase of blood sugar whereas in another experiment, in which there had been previous injection of adrenalin, ingestion of glucose was not followed by such an increase. In our experience, previous single injection of adrenalin or ingestion of food did not prevent the appearance of hyperglycemia though such increase presumably would have been greater if previous hyperglycemia had not been produced. Curves did not become normal until several days after the end of a fast. In several instances (see fig. 7 , patient 40 , curve $D$ ) three to six days after a fast patients presented a steeple type of curve, with a very high peak (up to $500 \mathrm{mgm}$ ) at the half-hour period. In other instances, as seen in figure 10 , the sugar curve gradually assumed its prefasting form.

We have no evidence to show whether the delay in the removal of excess sugar from the blood is due to delayed entrance into the tissues, to deficient oxidation or to delayed glycogen formation. Presumably, the last named factor is the most important.

Although the degree of hyperglycemia observed when sugar is fed to a fasting person is striking, such increase of sugar in the blood represents but a small fraction of the amount ingested. Take for example the experiment with patient 51, shown in figure 5. After 12 days of fasting, he ingested 100 grams of glucose. At the end of one hour the increased amount of oxygen consumed would account for the oxidation of approximately 2 grams of glucose, the increase of 150 $\mathrm{mgm}$. of glucose per $100 \mathrm{cc}$. of blood would account for approximately 10 grams. Of the remaining 88 grams of glucose, a portion remained in the stomach or intestines or had entered the tissues but presumably the larger part had been deposited as glycogen in the liver and the muscles.

Evidence concerning over-stimulation. Thus far we have presented evidence indicating that alimentary hyperglycemia may be due to the lack of previous stimulation of the sugar-utilizing mechanism, a con- 
dition which may be corrected by administration of glucose. On the other hand, the persistently high sugar curves of some of the subjects may represent previous over-stimulation of the pancreas. Figure 9 presents nine successive ingestion curves of patient 34 , a woman who showed no evidence of diabetes unless an increase of 28 pounds in weight during the period of observation may be so considered. It will be seen that with two exceptions successive curves were of similar

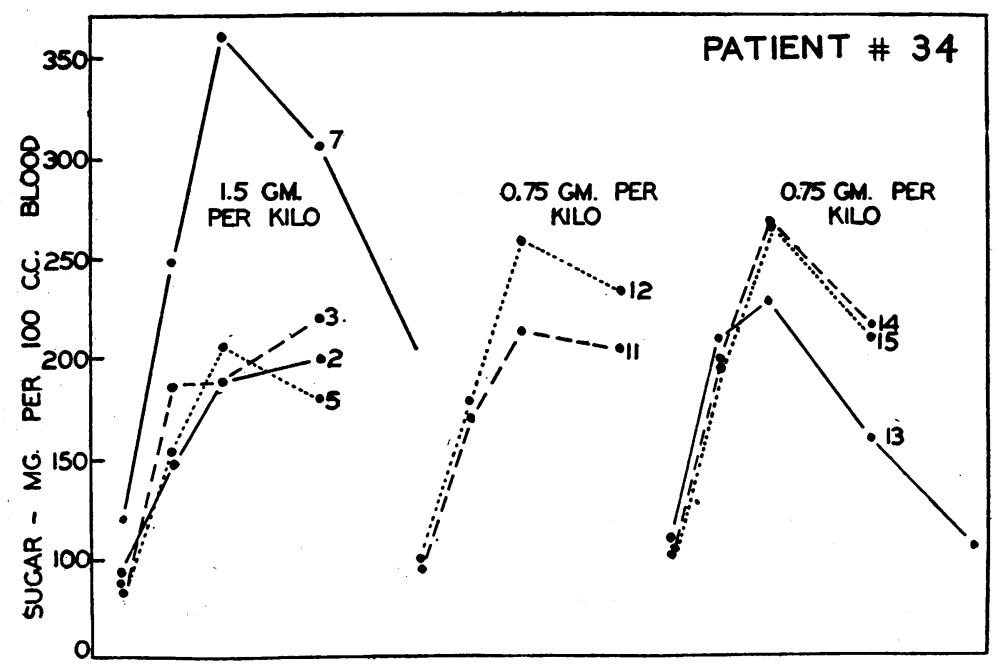

Fig. 9. Repeated Blood Sugar Curves of Patient Number 34, Following INGESTION OF GLUCOSE

The amount ingested for the last 5 curves was one-half the standard amount. Curve 7 was drawn the day after Christmas and curve 13 after several months of low carbohydrate diet. The period of observation covered 30 months, during which time the patient's weight increased from 155 to 183 pounds.

form and height. The highest curve, number 7, was obtained on the day following Christmas, when she had partaken largely of sweets. The lowest curve, number 13, was obtained following a four month period during which no glucose tests were performed and during which the patient was kept on a low carbohydrate diet. This observation is similar to some reported by John (22). Figure 10 represents successive curves of patient number 38 , whose blood sugar curves were high, but who had no symptoms of diabetes. The curves under $\mathbf{A}$ were 
obtained in a period of two weeks before fast was begun. B was obtained on the thirteenth day of a fast, and $\mathrm{C}$ on the third day after resumption of food. In addition to a mixed diet, the patient was then given 10 units of insulin twice daily for four days. On the fifth day curve $\mathrm{D}$ was obtained. This curve is very much flatter than any other. Six weeks later, during which time the subject was on his normal diet,

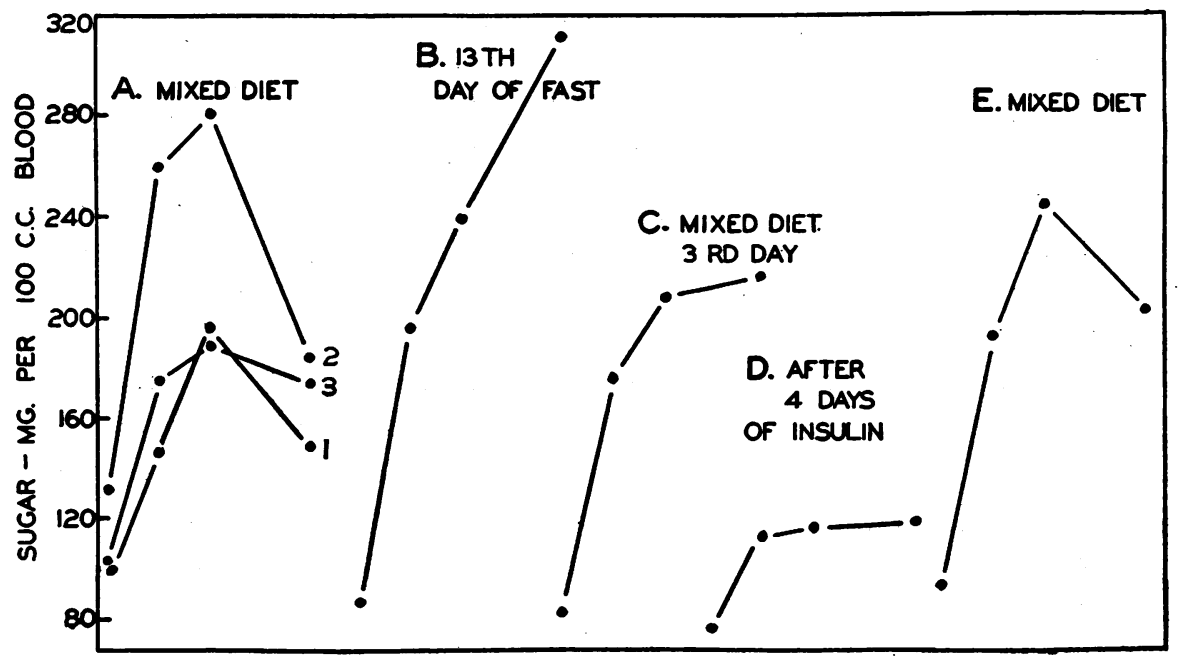

Fig. 10. Repeated Curves of Patient Number 38, Showing Contrasting EFFECT OF Fasting aNd INSULIN

Curves 1, 2 and 3 of A were obtained within a two-week period before the fast, curve $B$ after 13 days of the fast, which was complete except for the administration of 10 grams of glucose at intervals and of intarvin and cream, as stated under figure 6. Curve $\mathrm{C}$ was drawn following the fast after 3 days of mixed diet and curve $D 5$ days later after 4 days in which 10 units of insulin had been given night and morning and 18 hours after the last dose of insulin. Curve $\mathrm{E}$ was made 6 weeks later.

the curve was at its prefasting level. The contrast between curves B and $\mathrm{D}$ is striking. Evidently, stimulation of the sugar-utilizing mechanism was decreased by fasting and increased by previous use of insulin. Though these data are not extensive, they suggest that factors which partially rest the sugar-disposing mechanism in persons whose mechanism is incompetent (either because of inherent weakness or because of previous over-stimulation) result in lowering of the 
blood sugar curve, but that disuse of such mechanism, as in fasting, causes temporary increase in the blood sugar curve.

The question remains whether, as Maclean and de Wesselow (23) suggested, the hyperglycemia in itself is the stimulator of the sugarutilizing mechanism. Certain of our observations would make it seem probable that the matter should be stated more broadly. Probably the metabolism of carbohydrates rather than the simple presence of excess glucose in the blood is the factor of importance. In favor of this is the apparent increased rate of removal of glucose from the blood following the administration of thyroid extract and of insulin. It is possible, moreover, that protein, as well as carbohydrate metabolism, is concerned. Though Nord (24) obtained marked hyperglycemia following injection of certain amino acids, Bertram (25) has reported that the hypoglycemic action of insulin is enhanced by mixing it with various proteins. Vigneaud and Karr (19) found that feeding of protein even more than feeding of glucose increased the rate of removal of glucose in fasting. Finally, the factors which favor reduction of fasting postprandial hyperglycemia are curiously like the factors which we (26) have found to favor reduction of fasting hyperuricacidemia.

\section{DISCUSSION}

The data which have been presented would seem to make it clear that repeated blood sugar curves of persons with an initial high curve demonstrate two classes of individuals. The first and smaller group consists of those whose sugar-disposing mechanism has been over stimulated and whose blood sugar curves remain high or tend to become higher with successive tests. These persons presumably comprise the group from which diabetics are to be recruited. The second and larger group consists of those who present an initial high curve which tends to become progressively lower with repeated tests. These persons would seem to have a competent sugar-disposing mechanism which only needs adequate stimulation to be made effective, It is evident that a single high blood sugar curve test may be without diagnostic value. Whatever the explanation of a tendency toward lowering of successive curves, the fact that of our twenty-five subjects who had a high initial blood sugar curve, the second curve of twenty-one was lower, makes one loathe to conclude that a lowered 
second curve is necessarily due to treatment or to experimental procedure.

\section{CONCLUSIONS}

1. Repeated blood sugar curves, some 300 in number, have been made in a group of 50 non-diabetic subjects, at intervals of days or months.

2. In the majority of the subjects, there was progressive lowering of successive curves following both ingestion and injection of glucose. Of the 25 subjects with abnormally high initial blood sugar curves, 21 of the curves were lower on second trial. A single blood sugar curve test, therefore, may be without diagnostic significance, and a lowered subsequent curve may not necessarily be due to the experimental or therapeutic procedures introduced between the first and second tests.

3. The unduly prolonged hyperglycemia which follows ingestion of glucose and injection of adrenalin in fasting would seem to be due to the lack of stimulation of the sugar-regulating mechanism.

4. A minority of the subjects studied showed constant high blood sugar curves and presumably belong to the group of personsfrom which diabetics are to be recruited.

\section{BIBLIOGRAPHY}

1. Pemberton, R., and Foster, G. L., Arch. Int. Med., 1920, xxv, 243. Studies on Arthritis in the Army Based on 400 Cases. III. Studies in the Nitrogen, Urea, Carbon Dioxid Combining Power, Calcium, Total Fat and Cholesterol of the Fasting Blood, Renal Function, Blood Sugar and Sugar Tolerance.

2. Pemberton, R., Cajorie, F. A., and Crouter, C. Y., Jour. A. M. A., 1926, lxxxvii, 2148. The Influence of Focal Infection and the Pathology of Arthritis: Results of Experiments.

3. Cajorie, F. A., Crouter, C. Y., and Pemberton, R., Jour. Biol. Chem., 1925, Ixvi, 89. The Effect of Changes in the Circulation on Carbohydrate Utilization.

4. Labbe, M., Annalesde medicine, 1925, xvii, 116. L'épreuve d'hyperglycémie provoquéeson application a la clinique.

5. Berg, S., Acta Tuberc. Scandiniv., 1926, ii, 1. Blood Sugar; Amount in Patients with Pulmonary Tuberculosis.

6. Davidson, E. C., and Allen, C. I., Bull. Johns Hopkins Hospital, 1925, xxxvii, 217. The Blood Glucose Curve in Head Injuries. 
7. Mertz, A., and Rominger, E., Arch. für Kinderheilkunde, 1921, lxix, 81. Experimentelle Blutzuckeruntersuchungen bei Kindern.

8. Hale-White, R., and Payne, W. W., Quart. Jour. Med., 1926, xix, 393. The Dextrose Tolerance Curve in Health.

9. Niemeyer, R., Zeit. fur klinische Med., 1924, xcviii, 132. Über Blutzuckerreaktion.

10. Lennox, W. G., Arch. Neurol. and Psych. In Press. Studies of the Metabolism in Epilepsy. III. The Blood Sugar Curve.

11. Folin, O., and Wu, H., Jour. Biol. Chem., 1920, xli, 367. A Simplified and Improved Method for Determination of Sugar.

12. Evans, F. A., and Rothberg, V. E., Jour. Biol. Chem., 1923, lviii, 443. A Modified Folin and Wu Blood Sugar Method.

13. Beeler, C., Bryan, A. W., and Cathcart, E. P., Fitz, R., Jour. Met. Research, 1922, i, 549. An Improved Alimentary Glycose Tolerance Test.

14. Lennox, W. G., and Bellinger, M., Comparison of Blood Sugar Curves following Ingestion and Intravenous Injection of Glucose. In Press.

15. Lennox, W. G., and Bellinger, M., Stimulation of the Sugar Regulating Mechanism as shown by duplicate Blood Sugar Curves. In Press.

16. Staub, H., Zeit. fur Klin. Med., 1922, xciii, 89. Untersuchungen über den Zuckerstoffwechsel des, Menschen.

17. Traugott, K., Klin. Woch., 1922, i, 892. Utber das Verhalten des Blutzuckerspiegels bei wiederholter und verschiedener Art enteraler Zuckerzufuhr, und dessen Bedeutung für die Leberfunktion.

18. Severinghaus, E. L., Jour. Biol. Chem., 1925, lxiii, p. xlviii. The Effect of Fasting upon Carbohydrate Utilization.

19. Vigneaud, V., and Karr, W. G., Jour. Biol. Chem., 1925, lxvi, 281. Carbohydrate Utilization. 1. Rate of disappearance of d-Glucose from the Blood.

20. Henderson, Y., Physiol. Reviews, 1925, v, 131. Physiological Regulation of the Acid-base Balance of the Blood and Some Related Functions.

21. Lennox, W. G., Arch. Int. Med., 1926, xxxviii, 553. Chemical Changes in the Blood during Fasting in the Human Subject.

22. John, H. J., Jour. Met. Research, 1923, iv, 255. Glucose Tolerance and its Value in Diagnosis.

23. Maclean, H., and de Wesselow, O. L. V., Quart. Jour. Med., 1921, xiv, 103. The Estimation of Sugar Tolerance.

24. Nord, F., Acta Med. Scandinavica, 1926, lxv, 1. Étude sur l'influence de quelques derivés de l'albumine sur la régulation du sucre du sang.

25. Bertram, F., Klin. Wchschr., 1925, iv, 2285. Utber Aktivierung des Insulins durch Eiweisskörper.

26. Lennox, W. G., Jour. Biol. Chem., 1925, lxvi, 521. A Study of the Retention of Uric Acid during Fasting. 